\title{
Histone Acetyltransferases (HATs) Involved in Non-Homologous End Joining as a Target for Radiosensitization
}

\author{
Takahiro Oike, Hideaki Ogiwara, Takashi Nakano and Takashi Kohno
}

Additional information is available at the end of the chapter

http://dx.doi.org/10.5772/56555

\section{Introduction}

Radiation therapy is one of the most important treatment modalities for cancer therapy alongside surgery and chemotherapy. However, a major problem associated with radiation therapy in the clinical setting is that, in many cases, local control of the tumor cannot be achieved using this modality alone. This has driven researchers into radiosensitizers, i.e., compounds that enhance the intrinsic sensitivity of cancer cells to ionizing radiation (IR). Several compounds, including halogenated pyrimidines and nitroimidazole derivatives, show radiosensitizing effects in cancer cells [1]; however, clinical application of these compounds is limited because they are highly toxic to normal cell and tissues. Therefore, radiosensitizers with low toxicity to normal tissues are urgently needed.

The principal target for IR-induced killing of cancer cells is DNA [2]. Of the different types of DNA damage generated by IR, DNA double-strand breaks (DSBs) are thought to be the most cytotoxic. DSBs induced by IR are preferentially repaired by non-homologous end joining (NHEJ) [3, 4], which joins the two broken DNA ends without the need for sequence homology. To enable NHEJ, the chromatin needs to be remodeled into an 'open' state so that the DNA repair proteins can access the DSB sites [5]. We previously reported that acetylation of histone proteins at DSB sites by the histone acetyltransferases (HATs), TIP60, CBP and p300, facilitates NHEJ through chromatin remodeling [6]. This suggests that the inhibition of HAT activity will radiosensitize cancer cells by suppressing NHEJ. In line with this, we and others demonstrated that several natural compounds with HAT-inhibitory activity are able to radiosensitize cancer cells [6-12]. Since some of these compounds are safe when administered to humans [13-15], they could potentially be used as radiosensitizers in a clinical setting. Here, we discuss the role of HATs in NHEJ, the radiosensitizing effects of compounds with HAT-inhibitory activity, and the prospects for the clinical application of these compounds. 


\section{Radiosensitization by HAT inhibition}

\subsection{HATs are involved in chromatin remodeling required for DNA repair}

Chromosomal DNA and histones form a highly condensed structure known as chromatin. During the repair of DNA DSBs, the accessibility of DNA repair proteins to the DSB sites on chromosomal DNA is regulated by the relaxation of the chromosome structure via chromatin remodeling. Remodeling is mediated by both covalent (histone modifications, e.g., acetylation) and non-covalent (ATPase-dependent chromatin remodeling) interactions (Figure 1). Several studies show that the acetylation of histones located at the DSB sites is a critical step for DNA repair [16-18]; however, the HATs involved in NHEJ have not been fully identified.

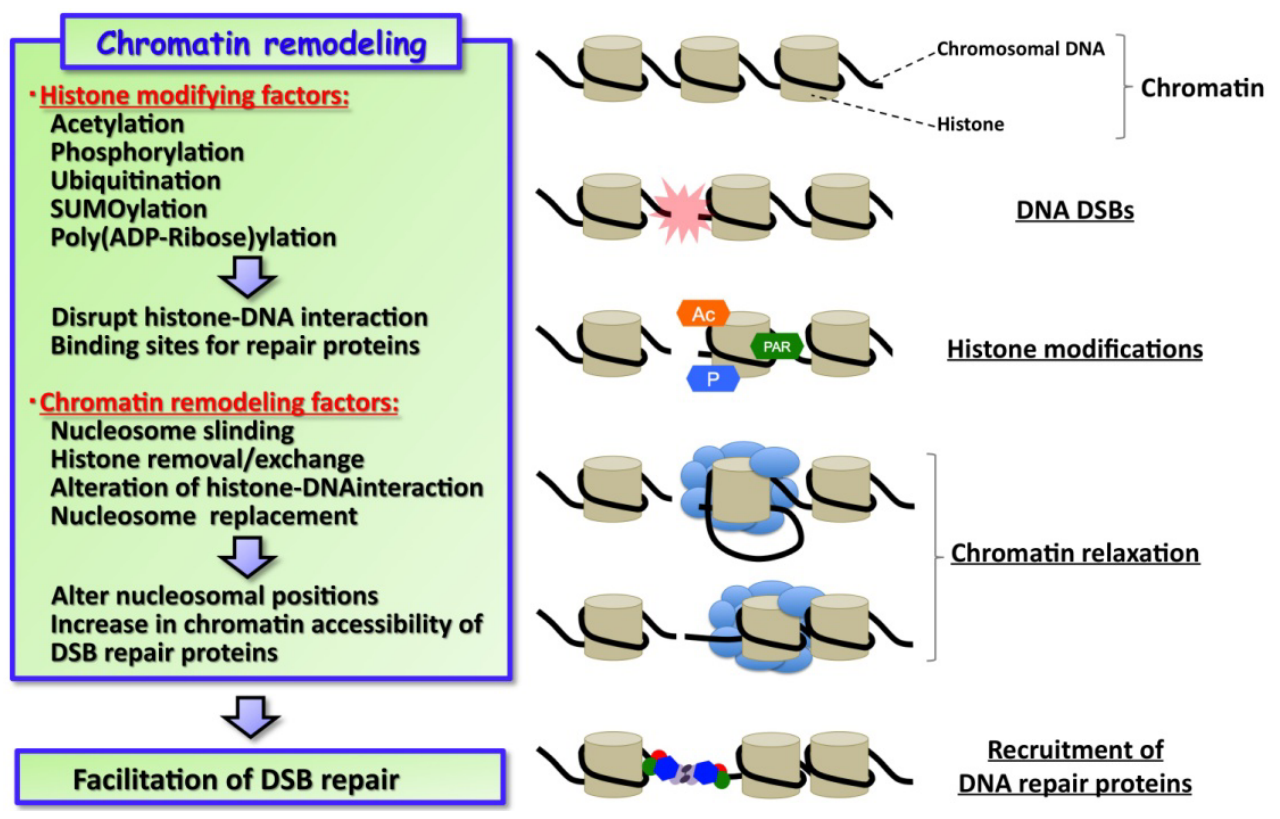

Figure 1. Chromatin remodeling is required for DSB repair. Both histone modifications and ATPasedependent chromatin remodeling are needed for efficient repair.

\subsection{Cell-based NHEJ activity assay}

We developed a new assay system for evaluating NHEJ repair of DSBs in the chromosomal DNA in living human cells $[6,18]$ because the existing NHEJ assays used only nonchromosomal (i.e., plasmid) DNA. The assay design is outlined in Figure 2. The IRES-TKEGFP plasmid, which contains two recognition sites for I-SceI endonuclease [20] in the 
reverse direction, was integrated into the chromosomal DNA of H1299 human lung cancer cells as a substrate for DSBs and subsequent NHEJ repair. Human genomic DNA does not contain I-SceI sites; therefore, the I-SceI protein transiently expressed after transfection of the I-SceI expression plasmid specifically cleaves the two I-SceI sites in the substrate DNA to yield DSBs with incompatible ends. This results in DSBs in the chromosomal DNA. NHEJ of the two broken DNA strands results in deletion of the herpes simplex virus-thymidine kinase (TK) open reading frame and leads to the production of a transcript that enables the translation of enhanced green fluorescent protein (EGFP) instead of the TK protein.
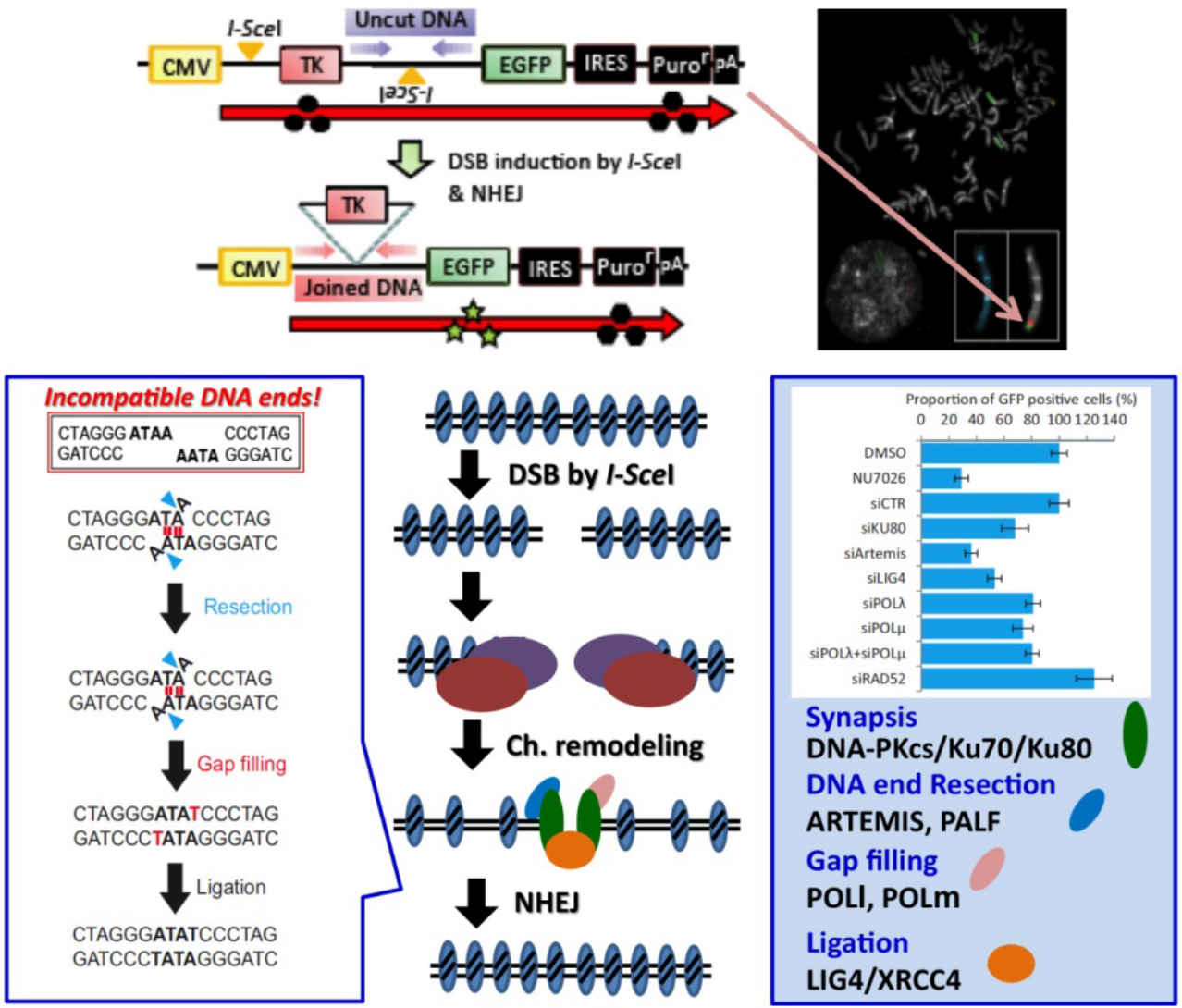

Figure 2. Cell-based NHEJ activity assay [6]. Upper panel: Assay design. Two I-SceI sites (in the reverse direction) are indicated by the yellow arrow heads. The locations of the PCR primers used for quantitative PCR to monitor DSB introduction by I-SceI (uncut DNA) and subsequent joining (joined DNA) are indicated by the purple and red arrows, respectively. CMV, cytomegalovirus promoter/enhancer; IRES, internal ribosome entry site; pA, polyA signal. Lower panel: Factors essential for NHEJ of DSBs on chromosomal DNA. 
Therefore, the efficiency of NHEJ can be assessed by monitoring EGFP production. In addition, the DSBs produced by I-SceI and the subsequent NHEJ of the two broken DNA strands can be monitored by quantitative PCR.

Nucleotide sequencing of the joined DNA revealed that ligation required no (or very little) sequence homology between the DNA ends, indicating that the DNA ends were joined via NHEJ. In addition, the contribution of other factors essential for the NHEJ of incompatible DNA ends (whose involvement was indicated by in vitro and in vivo plasmid-based assays) was also confirmed in the present chromosome-based in vivo assay. These factors are KU80 and DNA-PKcs (synapsis), Artemis and PALF (DNA end resection), POL $\lambda$ and POL $\mu$ (gap filling), and LIG4 (ligation) [21, 22].

\subsection{HATs involved in NHEJ}

To date, several distinct families of HAT proteins have been identified, including CBP, P300, PCAF, GCN5 and MYST (which includes TIP60) [23]. We investigated the effects of ablating CBP , P300, PCAF and TIP60 on NHEJ using the cell-based NHEJ activity assay. A decrease in the number of EGFP-positive cells was observed upon transfection with siRNA specific for $C B P, P 300$ or TIP60, but not in cells transfected with siRNA specific for PCAF [6]. These results indicate that CBP, P300 and TIP60 are involved in NHEJ in human cells.

\subsection{Natural compounds with HAT activity suppress NHEJ activity}

Several compounds derived from natural ingredients show HAT-inhibitory activity (Table 1). Curcumin, a major curcumanoid found in the spice turmeric, is a specific inhibitor of the homologous HATs, CBP and P300 [24]. Anacardic acid, derived from the shell of Anacardium occidentale ('cashew nut'), inhibits P300, PCAF and TIP60 [7, 25, 26], and Garcinol, found in the rind of Garcinia indica (mangosteen), inhibits P300 and PCAF [27].

\begin{tabular}{|c|c|c|c|c|}
\hline Compound & $\mathrm{MW}^{1}$ & $\begin{array}{l}\text { Target } \\
\text { HATs }\end{array}$ & Other target proteins/pathways & $\mathrm{DER}^{2}$ \\
\hline Curcumin & 368.38 & CBP, P300 & $\begin{array}{l}\text { NF-кB pathway, PI3K/mTOR/ETS2 } \\
\text { pathway, AP-1 STAT, LOX-1 }\end{array}$ & 1.23 \\
\hline $\begin{array}{l}\text { Anacardic } \\
\text { acid }\end{array}$ & 342.47 & $\begin{array}{l}\text { P300, PCAF, } \\
\text { TIP60 }\end{array}$ & NF- $\mathrm{B}$ pathway, LOX-1, Xanthine oxidase, & 1.51 \\
\hline Garcinol & 602.80 & P300, PCAF & $\begin{array}{l}\text { NF-kB pathway, Src, MAPK/ERK, PI3K/Akt } \\
\text { pathways, topoisomerase I/II }\end{array}$ & 1.61 \\
\hline
\end{tabular}

${ }^{1}$ Molecular weight; ${ }^{2}$ Dose enhancement ratio (as assessed in cell viability assays [8]).

Table 1. HAT inhibitors that suppress NHEJ in human cells.

The cell-based NHEJ activity assay was used to investigate the effects of curcumin, anacardic acid, and garcinol on NHEJ; the results showed that treatment with each compound decreased the proportion of EGFP-positive cells (Figure 3) [6, 8]. This indicates that these HAT inhibitors suppress NHEJ activity in vivo. 

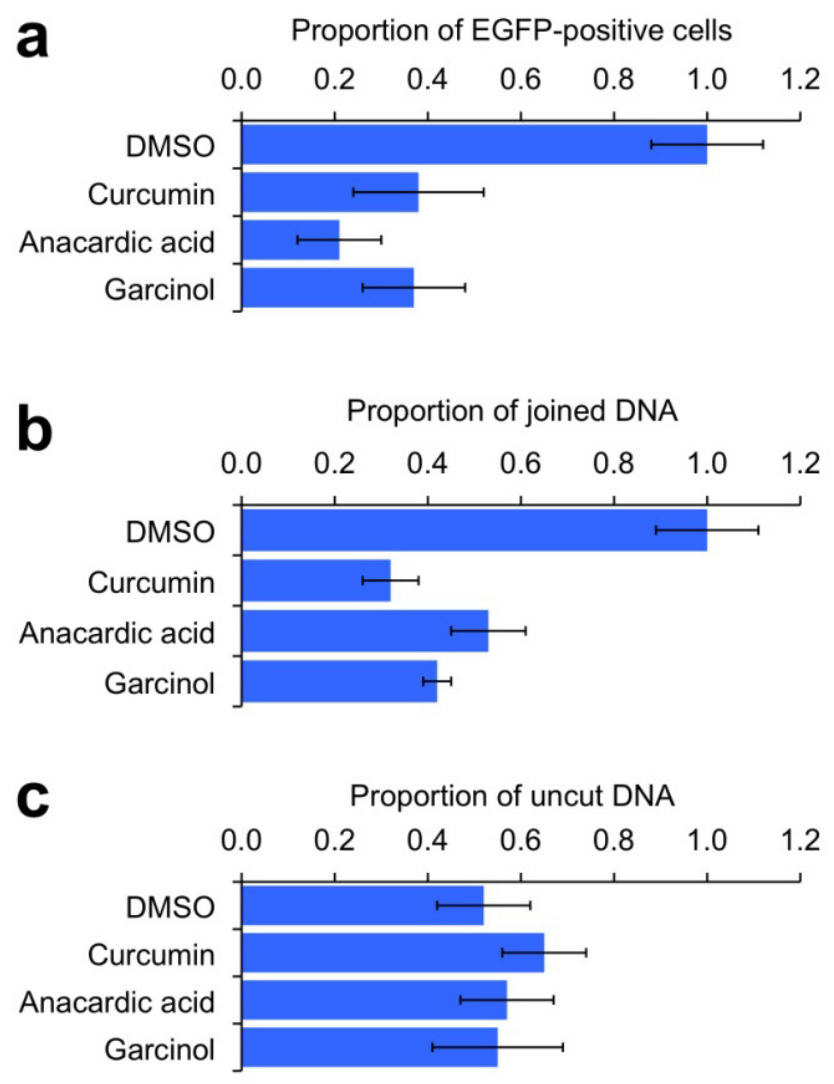

Figure 3. Suppression of NHEJ by HAT inhibitors [6, 8]. H1299-dA3-1 \#1 cells pretreated with curcumin $(20 \mu \mathrm{M})$, anacardic acid $(50 \mu \mathrm{M})$, or garcinol $(12 \mu \mathrm{M})$ were transfected with the I-SceI expression plasmid. (a) The proportion of EGFP-positive cells assessed by fluorescence-activated cell sorting analysis. $(b, c)$ Proportion of joined (b) and uncut (c) DNA in cells assessed by quantitative PCR. The proportion of EGFP-positive cells and the proportion of joined DNA after garcinol treatment versus those in cells treated with DMSO (expressed as a ratio). The proportion of uncut DNA remaining after drug treatment expressed as a ratio of the amount of uncut DNA present after I-SceI transduction versus the amount present before transduction. Results $48 \mathrm{~h}$ after transfection of the I-SceI expression plasmid are shown. The results represent the mean \pm s.d from three independent experiments. siCTR, nontargeting siRNA. 


\subsection{HAT inhibitors radiosensitize cancer cells}

Because DNA DSBs induced by IR are preferentially repaired by NHEJ [3, 4], and HAT inhibitors suppress the activity of NHEJ, it is thought that HAT inhibitors may enhance the intrinsic sensitivity of cancer cells to IR. In line with this, the radiosensitizing effects of curcumin, anacardic acid and garcinol have been studied by ourselves and others both in vitro and in vivo (see Table 2); however, it is not certain that the observed radiosensitizing effects of these compounds is entirely due to their HAT-inhibitory activity, since they may also affect many other proteins or pathways considered to be important for the cancer cell survival (see Table 1). In our own study, garcinol showed the strongest radiosensitization effect of the compounds tested. A nontoxic concentration of garcinol (4 uM) inhibited NHEJ without significantly affecting the DNA damage checkpoint (Table 1) [8]. Further investigations into mechanisms underlying the radiosensitizing effects of HAT inhibitors are ongoing.

\begin{tabular}{|c|c|c|c|c|c|}
\hline Compound & Cells/mice & Cell lines & Authors & Year & Journal \\
\hline \multirow[t]{4}{*}{ Curcumin } & $\begin{array}{l}\text { Cells \& } \\
\text { mice }\end{array}$ & SCC1 & Khafif A, et al.[9] & 2009 & The Laryngoscope \\
\hline & Cells & HCT116 & Sandur SK, et al.[10] & 2009 & $\begin{array}{l}\text { Int J Radiat Oncol } \\
\text { Biol Phys }\end{array}$ \\
\hline & Cells & PC-3 & Li M, et al.[11] & 2007 & Cancer Res \\
\hline & Cells & PC-3 & Chendil D, et al.[12] & 2004 & Oncogene \\
\hline $\begin{array}{l}\text { Curcumin } \\
\text { /anacardic acid }\end{array}$ & Cells & H1299 & Ogiwara $\mathrm{H}$, et al.[6] & 2011 & Oncogene \\
\hline Anacardic acid & Cells & $\begin{array}{l}\text { SQ20B, } \\
\text { SCC35, } \\
\text { HeLa }\end{array}$ & Sun $Y$, et al.[7] & 2006 & FEBS Lett \\
\hline Garcinol & Cells & A549, HeL & Oike, et al.[8] & 2012 & $\begin{array}{l}\text { Int J Radiat Oncol } \\
\text { Biol Phys }\end{array}$ \\
\hline
\end{tabular}

Table 2. Radiosensitization by HAT inhibitors.

\subsection{Clinical studies using compounds with HAT-inhibitory activity}

There are several clinical studies reporting the administration of compounds with HATinhibitory to humans (Table 3). Curcumin has been used, either alone or combined with radiation therapy and/or chemotherapeutic agents, to treat cancer patients, and garcinol has been used for weight-loss therapy. Although not all of the studies were designed to specifically evaluate the radiosensitizing effects of these compounds, the data will be of help to estimate their toxicity. The available data indicate that the side effects of these compounds are tolerable, at least when used alone. 


\begin{tabular}{|c|c|c|c|c|}
\hline Compound & Disease & Phase & Modality & Sponsor/Author \\
\hline Curcumin & Rectal cancer* & II & $\begin{array}{l}\text { Curcumin, } \mathrm{RT}^{1}, \\
\text { capecitabine } v s . \mathrm{RT}^{1}, \\
\text { capecitabine }\end{array}$ & $\begin{array}{l}\text { M.D. Anderson } \\
\text { Cancer Center }\end{array}$ \\
\hline Curcumin & $\begin{array}{l}\text { Pancreatic } \\
\text { cancer* }\end{array}$ & II & $\begin{array}{l}\text { Curcumin, gemcitabine } v s . \\
\text { gemcitabine }\end{array}$ & $\begin{array}{l}\text { Rambam } \\
\text { Healthcare Campus }\end{array}$ \\
\hline Curcumin & $\begin{array}{l}\text { Pancreatic } \\
\text { cancer* }^{*}\end{array}$ & II & Curcumin alone & $\begin{array}{l}\text { M.D. Anderson } \\
\text { Cancer Center }\end{array}$ \\
\hline Curcumin & Colorectal cancer & I & Curcumin alone & $\begin{array}{l}\text { Sharma RA, et } \\
\text { al.[13] }\end{array}$ \\
\hline Curcumin & $\begin{array}{l}\text { Healthy } \\
\text { volunteer }\end{array}$ & I & Curcumin alone & Lao CD, et al.[14] \\
\hline Garcinol & Obesity $^{* *}$ & II & $\begin{array}{l}\text { Garcinol, } \mathrm{HCA}^{2} \text { acid } v s . \\
\mathrm{HCA}^{2}\end{array}$ & $\begin{array}{l}\text { Sabinsa } \\
\text { Corporation }\end{array}$ \\
\hline Garcinol & Obesity & II & $\begin{array}{l}\text { Garcinol, } \mathrm{HCA}^{2} \text {, forskolin, } \\
\text { piperine }\end{array}$ & Majeed M, et al.[15] \\
\hline
\end{tabular}

Details on the clinical trials are available for inspection at:

*http://www.clinicaltrials.gov/ and **http://www.garcitrin.com/clinical/.

${ }^{1}$ Radiation therapy, ${ }^{2} \mathrm{Hydroxycitric}$ acid.

Table 3. Clinical studies using compounds with HAT-inhibitory activity.

\section{Conclusions/perspectives}

The growing incidence of cancer worldwide indicates that radiation therapy will become increasingly significant as a cancer treatment [28]. Enhancing the efficacy of IR against cancer cells is urgent needs local control of tumors. As discussed in this article, radiosensitization of cancer cells by compounds with HAT-inhibitory activity has been reported at the level of basic research. Clinical studies indicate that some of these compounds can be administered to human patients with low systemic toxicity. Taken together, the available data suggest that compounds with HAT-inhibitory activity are promising candidates for radiosensitizers that may be applicable in clinical settings. However, the detailed mechanisms by which these compounds radiosensitize cancer cells are still largely unknown. Moreover, it is unclear whether these compounds can achieve adequate levels of radiosensitization in humans at a dose that shows no (or at least low) toxicity. Further investigations will establish whether HAT inhibitors can be used clinically to radiosensitize cancer cells. 


\section{Author details}

Takahiro Oike

Division of Genome Biology, National Cancer Center Research Institute, Tokyo, Japan

Department of Radiation Oncology, Gunma University Graduate School of Medicine, Gunma, Japan

Hideaki Ogiwara and Takashi Kohno*

Division of Genome Biology, National Cancer Center Research Institute, Tokyo, Japan

Takashi Nakano

Department of Radiation Oncology, Gunma University Graduate School of Medicine, Gunma, Japan

\section{Acknowledgement}

This work was supported by Grants-in-Aid from the Ministry of Education, Culture, Sports, Science and Technology of Japan for Scientific Research on Innovative Areas (22131006) and from the Japan Society for the Promotion of Science for Young Scientists (B) KAKENHI (23701110); and the National Cancer Center Research and Development Fund.

\section{References}

[1] Hall EJ, Giaccia AJ. (2006) Radiosensitizers and bioreductive drugs. In: McAllister L, Bierig L, Barret K, editors. Radiobiology for the radiologist. Philadelphia: Lippincott Williams \& Wilkins. pp. 419-431.

[2] Hall EJ, Giaccia AJ. (2006) DNA strand breaks and chromosomal aberrations. In: McAllister L, Bierig L, Barret K, editors. Radiobiology for the radiologist. Philadelphia: Lippincott Williams \& Wilkins. pp. 16-29.

[3] Burma S, Chen BPC, Chen DJ, et al. (2006) Role of non-homologous end joining (NHEJ) in maintaining genomic integrity. DNA Repair. 8:1042-1048.

[4] Lieber MR. (2008) The mechanism of human nonhomologous DNA end joining. J. Biol. Chem. 283:1-5.

[5] Rossetto D, Truman AW, Kron SJ, et al. (2010) Epigenetic modifications in double-strand break DNA damage signaling and repair. Clin. Cancer. Res. 15:4543-4552.

[6] Ogiwara H, Ui A, Otsuka A, et al. (2011) Histone acetylation by CBP and p300 at double-strand break sites facilitates SWI/SNF chromatin remodeling and the recruitment of non-homologous end joining factors. Oncogene. 5:2135-2146.

[7] Sun Y, Jiang X, Chen S, et al. (2006) Inhibition of histone acetyltransferase activity by anacardic acid sensitizes tumor cells to ionizing radiation. FEBS Lett. 580:4353-4356.

[8] Oike T, Ogiwara H, Torikai K, et al. (2012) Garcinol, a histone acetyltransferase inhibitor, radiosensitizes cancer cells by inhibiting non-homologous end joining. Int. J. Radiat. Oncol. Biol. Phys. in press.

\footnotetext{
${ }^{*}$ Corresponding Author
} 
[9] Khafif A, Lev-Ari S, Vexler A, et al. (2009) Curcumin: a potential radio-enhancer in head and neck cancer. Laryngoscope. 119:2019-2026.

[10] Sandur SK, Deorukhkar A, Pandey MK, et al. (2009) Curcumin modulates the radiosensitivity of colorectal cancer cells by suppressing constitutive and inducible NF$\kappa \mathrm{B}$ activity. Int. J. Radiat. Oncol. Biol. Phys. 75:534-542.

[11] Mao Li, Zhuo Zhang, Donald L. Hill, et al. (2007) Curcumin, a dietary component, has anticancer, chemosensitization, and radiosensitization effects by down-regulating the MDM2 oncogene through the PI3K/mTOR/ETS2 pathway. Cancer Res. 67:1988-96.

[12] Chendil D, Ranga RS, Meigooni D, et al. (2004) Curcumin confers radiosensitizing effect in prostate cancer cell line PC-3. Oncogene. 23:1599-1607.

[13] Sharma RA, Euden SA, Platton AL, et al. (2004) Phase I clinical trial of oral curcumin biomarkers of systemic activity and compliance. Clin. Cancer Res. 10:6847-1854.

[14] Lao CD, Ruffin MT, Normolle D, et al. (2006) Dose escalation of a curcuminoid formulation. BMC Complment Altern. Med. 6:10.

[15] Majeed M, Badmaev V, Khan N, et al. (2009) A new class of phytonutrients for body weight management. NUTRAfoods 8:17-26.

[16] Bird AW, Yu DY, Pray-Grant MG, et al. (2002) Acetylation of histone H4 by Esa1 is required for DNA double-strand break repair. Nature. 419:411-415.

[17] Tamburini BA, Tyler JK. (2005) Localized histone acetylation and deacetylation triggered by the homologous recombination pathway of double-strand DNA repair. Mol. Cell. Biol. 25:4903-4913.

[18] Murr R, Loizou JI, Yang YG, et al. (2006) Histone acetylation by Trrap-Tip60 modulates loading of repair proteins and repair of DNA double-strand breaks. Nat. Cell. Biol. 8:91-99.

[19] Lan L, Ui A, Nakajima S, Hatakeyama K, Hoshi M, Watanabe R, Janicki S, Ogiwara H, Kohno T, Kanno S, Yasui A. The ACF1 complex is required for DNA double-strand break repair in human cells. Mol Cell 2010, 40: 976-987.

[20] Jasin M. (1996) Genetic manipulation of genomes with rare-cutting endonucleases. Trends Genet. 12:224-228.

[21] Ogiwara H, Kohno T. Essential factors for incompatible DNA end joining at chromosomal DNA double strand breaks in vivo. PLoS One, 2011, 6(12) e28756.

[22] Li S, Kanno S, Watanabe R, Ogiwara H, Kohno T, Watanabe G, Yasui A, Lieber MR. PALF acts as both a single-stranded DNA endonuclease and a single-stranded DNA 3' -exonuclease and can participate in DNA end joining in a biochemical system. J Biol Chem. 2011,286:36368-77.

[23] Carrozza MJ, Utley RT, Workman JL, et al. (2003) The diverse functions of histone acetyltransferase complexes. Trends Genet. 19:321-329.

[24] Balasubramanyam K, Varier RA, Altaf M, et al. (2004) Curcumin, a novel p300/CREBbinding protein-specific inhibitor of acetyltransferase, represses the acetylation of histone/nonhistone proteins and histone acetyltransferase-dependent chromatin transcription. J. Biol. Chem. 279:51163-51171. 
[25] Hemshekhar M, Sebastin SM, Kemparaju K, et al. (2011) Emerging roles of anacardic acid and its derivatives: a pharmacological overview. Basic Clin. Pharmacol. Toxicol. doi: 10.1111/j.1742-7843.2011.00833.x. [Epub ahead of print]

[26] Balasubramanyam K, Swaminathan V, Ranganathan A, et al. (2003) Small molecule modulators of histone acetyltransferase p300. J. Biol. Chem. 278:19134-19140.

[27] Balasubramanyam K, Altaf M, Varier RA, et al. (2004) Polyisoprenylated benzphenone, garcinol, anatural histone acetyltransferase inhibitor, represses chromatin transcription and alters global gene expression. J. Biol. Chem. 279:33716-33726.

[28] Boyle P. and Leon B. (2008) World Cancer Report 2008. Lyon: International agency for research on Cancer, World Health Organization. 15 p. 